\title{
Serum TSH Level in Healthy Koreans and the Association of TSH with Serum Lipid Concentration and Metabolic Syndrome
}

\author{
Yeo Kyung Lee', Jo Eun Kim', Hyun Ju Oh', Kyung Sun Park' ${ }^{1}$, Soo Kyung Kim', Seok Won Park ${ }^{1}$, Moon Jong Kim², \\ and Yong Wook Cho'
}

${ }^{1}$ Divison of Endocrinology and Metabolism, Department of Internal Medicine, ${ }^{2}$ Department of Family Medicine, CHA University College of Medicine, Seongnam, Korea

Background/Aims: The proper treatment of subclinical hypothyroidism and the normal range of serum thyroid stimulating hormone (TSH) concentration are intensely debated. However, few reports have investigated TSH concentrations in Asian ethnic groups. Therefore, the present study was designed to define the TSH reference range in a Korean population and to investigate the metabolic significance of TSH concentration.

Methods: We enrolled patients who underwent medical examination at the CHA Bundang Medical Center. Anthropometric data were evaluated, and serum TSH, free T4, and lipid profiles were assayed.

Results: A total of 7,270 subjects were included. Mean TSH concentration of the study population was $1.82 \pm 0.95 \mathrm{mU} / \mathrm{L}$, and we observed a sex-related difference in TSH concentration (male, $1.67 \pm 0.87 \mathrm{mU} / \mathrm{L}$; female, $2.02 \pm 1.01 \mathrm{mU} / \mathrm{L} ; p<0.01$ ). When the 2.5 and 97.5 percentiles were calculated, $95 \%$ TSH reference limits were $0.52-4.29 \mathrm{mU} / \mathrm{L}$. TSH concentration was higher in elderly subjects, during winter, in postmenopausal women, and in obese males. Moreover, TSH showed significantly positive correlations with serum total cholesterol, triglyceride, and low density lipoprotein cholesterol regardless of sex, age, season, obesity, or menopausal status (all $p<0.01$ ). Finally, TSH concentration was positively related to the prevalence of metabolic syndrome.

Conclusions: We demonstrated the association between TSH concentration within the normal reference range and serum lipid levels. TSH concentration varies according to sex, age, season, and body mass index (only in males). Moreover, high normal TSH levels were significantly associated with an increased prevalence of metabolic syndrome, which may be of importance when evaluating subjects with high normal TSH concentration.

Keywords: Thyroid function tests; Thyrotropin; Metabolic syndrome

\section{INTRODUCTION}

Thyroid stimulating hormone (TSH) which is secreted by the pituitary gland, has an inverse logarithmic relationship with free thyroxine (fT4) [1]. Because small changes in serum $\mathrm{fT}_{4}$ concentration can lead to more dramatic changes in serum TSH, measurement of the latter is one of the most sensitive methods of screening for thyroid dysfunction [2]. The laboratory reference range is usually defined by using the $95 \%$ confidence limits of a popula-

Received : March 28, 2011

Revised : June 2, 2011

Accepted: July 1, 2011

Correspondence to Yong Wook Cho, M.D.

Division of Endocrinology and Metabolism, Department of Internal Medicine, CHA Bundang Medical Center, CHA University College of Medicine, Yatapdong, Bundang-gu, Seongnam 463-712, Korea

Tel: 82-31-780-5215, Fax: 82-31-780-5208, E-mail: ywcho@cha.ac.kr 
tion of subjects without known thyroid dysfunction. Some reports define the lower limit of TSH as 0.2-0.4 mU/L and the upper limit as 2.4-4.2 mU/L [1,2]. The third National Health and Nutrition Examination Survey NHANES III (1988-1994) found that the laboratory reference range, defined from values in the normal population, was 0.4-4.12 $\mathrm{mU} / \mathrm{L}$. Results also showed ethnic difference in TSH concentration among White, Black, and Mexican American respondents. Therefore, questions are increasingly being raised over whether the normal range of TSH concentrations in Asians is similar to that in Caucasians.

With the increasing awareness of subclinical forms of hyperthyroidism and hypothyroidism and increasing concern about thyroid disease in Korea, routine health examinations that include thyroid function are increasingly popular. There are few controversies regarding diagnosis and management of subclinical hyperthyroidism, as the adverse effects of subclinical hyperthyroidism such as osteoporosis, cardiovascular disease, and arrhythmia are well-known [3]. In contrast, the definition of subclinical hypothyroidism with reference to the normal TSH concentration range remains debated [4-6].

Overt thyroid disease is associated with atherosclerotic cardiovascular disease; this is an unambiguous sign of overt hypothyroidism $[7,8]$ and results from hypercholesterolemia and elevated blood pressure. However, whether subjects with subclinical hypothyroidism, defined as an elevated serum TSH and normal range of fT4, have such adverse cardiovascular disease remains uncertain and controversial. Several studies have reported that serum cholesterol level is elevated in patients with subclinical hypothyroidism $[9,10]$ and is reversed by L-thyroxine treatment $[10,11]$. Another report suggested that the lipid profile of hypercholesterolemic patients with TSH levels between 2 and $4 \mathrm{mU} / \mathrm{L}$, currently regarded as a normal TSH concentration, improved after low-dose L-thyroxine treatment [12]. Considering that metabolic syndrome represents a cluster of cardiovascular risk factors and that subjects who are at risk for developing cardiovascular disease are euthyroid, whether TSH contributes to metabolic syndrome should be investigated.

In this study we report the TSH reference range in a Korean population and the metabolic significance of TSH concentration. We aimed to investigate the factors associated with TSH concentration and the relationship between TSH and lipid concentration. We also evaluated the impact of TSH concentration on the prevalence of metabolic syndrome.

\section{METHODS}

\section{Participants}

From January to December, 2006, 12,143 subjects were recruited from the medical examination center at the CHA Bundang Medical Center in Korea. All subjects (male, 57.3\%; female, 42.7\%) were older than 19 years and in good health, and none was pregnant. All completed a health questionnaire that included smoking, alcohol use, menopausal status, past medical history, and the use of thyroxine or antithyroid and lipid lowering medication. Hospital records were also checked to identify and exclude patients with serious systemic diseases not reported in the questionnaire. Among 12,143 subjects, 4,161 lacking a fT4 or lipid profile, 109 reported to have had thyroid disease, 503 who showed thyroid dysfunction, and 100 who were taking anti-hyperlipidemic medication were excluded. Finally, 7,270 subjects were included in the analysis.

\section{Definitions}

Euthyroidism was defined as a TSH within the reference range of 0.35-5.5 mU/L and $\mathrm{fT}_{4}$ within the reference range of $0.89-1.76 \mathrm{ng} / \mathrm{dL}$ (to convert to $\mathrm{pmol} / \mathrm{L}$, multiply by 12.871). Height and weight were measured with participants in light clothing wearing no shoes and was recorded to the nearest $0.1 \mathrm{~cm}$ and $0.1 \mathrm{~kg}$. Waist circumference was measured at the midpoint between the lateral iliac crest and the lowest rib. Body mass index (BMI) was calculated as weight in kilograms divided by the square of height in meters. Obesity was defined as a BMI $\geq 25 \mathrm{~kg} / \mathrm{m}^{2}$, as proposed by the Asia-Pacific obesity guidelines [13].

Smoking status at baseline was defined as never, previous, or current smoking. Blood pressure was measured at the right upper arm with a random-zero mercury sphygmomanometer in the sitting position. Seasons were defined as follows: spring, from March to May; summer, from June to August; fall, from September to November; and winter, from December to February. According to the Adult Treatment Panel (ATP) III criteria [14], metabolic syndrome was defined as the presence of any three of the following: waist circumference greater than $90 \mathrm{~cm}$ in males or $80 \mathrm{~cm}$ in females, triglycerides of $150 \mathrm{mg} / \mathrm{dL}$ (1.7 
$\mathrm{mmol} / \mathrm{L}$ ) or more, high-density lipoprotein (HDL) cholesterol less than $40 \mathrm{mg} / \mathrm{dL}(1.0 \mathrm{mmol} / \mathrm{L})$ in males or 50 $\mathrm{mg} / \mathrm{dL}(1.3 \mathrm{mmol} / \mathrm{L})$ in females, blood pressure of $130 / 85$ $\mathrm{mmHg}$ or higher, or fasting glucose of $100 \mathrm{mg} / \mathrm{dL}$ (5.6 $\mathrm{mmol} / \mathrm{L}$ ) or higher.

\section{Laboratory analysis}

All blood samples were drawn from an antecubital vein after at least 10 hours fasting. TSH and $\mathrm{fT}_{4}$ levels were analyzed using a commercial chemiluminescent assay (Advia Centaur, Bayer, Tarrytown, NY, USA). Fasting blood glucose, total cholesterol, triglyceride, and HDL cholesterol levels were assayed using an enzymatic method (Roche Diagnostics, Mannheim, Germany). Low-density lipoprotein (LDL) cholesterol was calculated using Friedewald's formula.

\section{Statistical analysis}

Data are expressed as the mean \pm SD unless otherwise stated. An independent-sample $t$ test was used for each comparison between two independent groups. Analysis of variance (ANOVA) with post hoc analysis according to Tukey was used to compare data among age groups and seasons. Multiple linear regression was used for association between lipid profile and TSH concentration with and without adjustment for age, sex, smoking status, obesity, menopause status, and season. Multiple regression analysis was used to assess the independent association between TSH and serum lipid profile, adjusting for various risk factors. To examine the effect of TSH concentration on metabolic syndrome, the cohort was further categorized into five groups according to TSH concentration and analyzed by logistic regression. For all analyses, overall $p$ values for trends are reported, and significance was assumed at $p<0.05$. Analyses were conducted with SPSS version 11.o (SPSS Inc., Chicago, IL, USA).

Table 1. Baseline characteristics of the study population $(n=7,270)$

\begin{tabular}{|c|c|c|}
\hline Characteristics & $\begin{array}{c}\text { Male } \\
(n=4,168)\end{array}$ & $\begin{array}{c}\text { Female } \\
(n=3,102)\end{array}$ \\
\hline Age, yr & $44.2 \pm 8.7$ & $43.4 \pm 9.8$ \\
\hline Age group, yr & $89(2.1)$ & $149(4.8)$ \\
\hline \multicolumn{3}{|l|}{$\leq 29$} \\
\hline $30-39$ & $75(30.6)$ & $1,038(33.5)$ \\
\hline $40-49$ & $1,841(44.2)$ & $1,236(39.8)$ \\
\hline $50-59$ & $735(17.6)$ & $439(14.2)$ \\
\hline$\geq 60$ & $228(5.5)$ & $240(7.7)$ \\
\hline Hypertension, mmHg & $410(9.8)$ & $153(4.9)$ \\
\hline Systolic blood press & $121.9 \pm 13.4$ & $114.0 \pm 13.6$ \\
\hline Diastolic blood press & $80.8 \pm 10.9$ & $63.7 \pm 10.3$ \\
\hline Waist circumference, $\mathrm{cm}$ & $82.1 \pm 9.1$ & $78.9 \pm 8.0$ \\
\hline Height, cm & $171.1 \pm 5.9$ & $158.7 \pm 5.3$ \\
\hline Weight, kg & $71.3 \pm 9.9$ & $55.9 \pm 7.4$ \\
\hline Body mass index, $\mathrm{kg} / \mathrm{m}^{2}$ & $24.4 \pm 3.2$ & $22.3 \pm 3.1$ \\
\hline Serum glucose, mg/dL & $94.8 \pm 17.4$ & $89.2 \pm 12.0$ \\
\hline Diabetes & $112(2.7)$ & $44(1.4)$ \\
\hline Impaired fasting glucose & $389(9.3)$ & $130(4.2)$ \\
\hline Total cholesterol, mg/dL & $191.4 \pm 32.9$ & $181.4 \pm 32.5$ \\
\hline Triglyceride, mg/dL & $149.6 \pm 92.5$ & $96.6 \pm 54.9$ \\
\hline High-density lipoprotein cholesterol, mg/dL & $46.7 \pm 9.9$ & $55.0 \pm 11.5$ \\
\hline Low-density lipoprotein cholesterol, mg/dL & $123.7 \pm 29.2$ & $112.1 \pm 28.7$ \\
\hline
\end{tabular}

Values are presented as mean \pm SD or number (\%). 


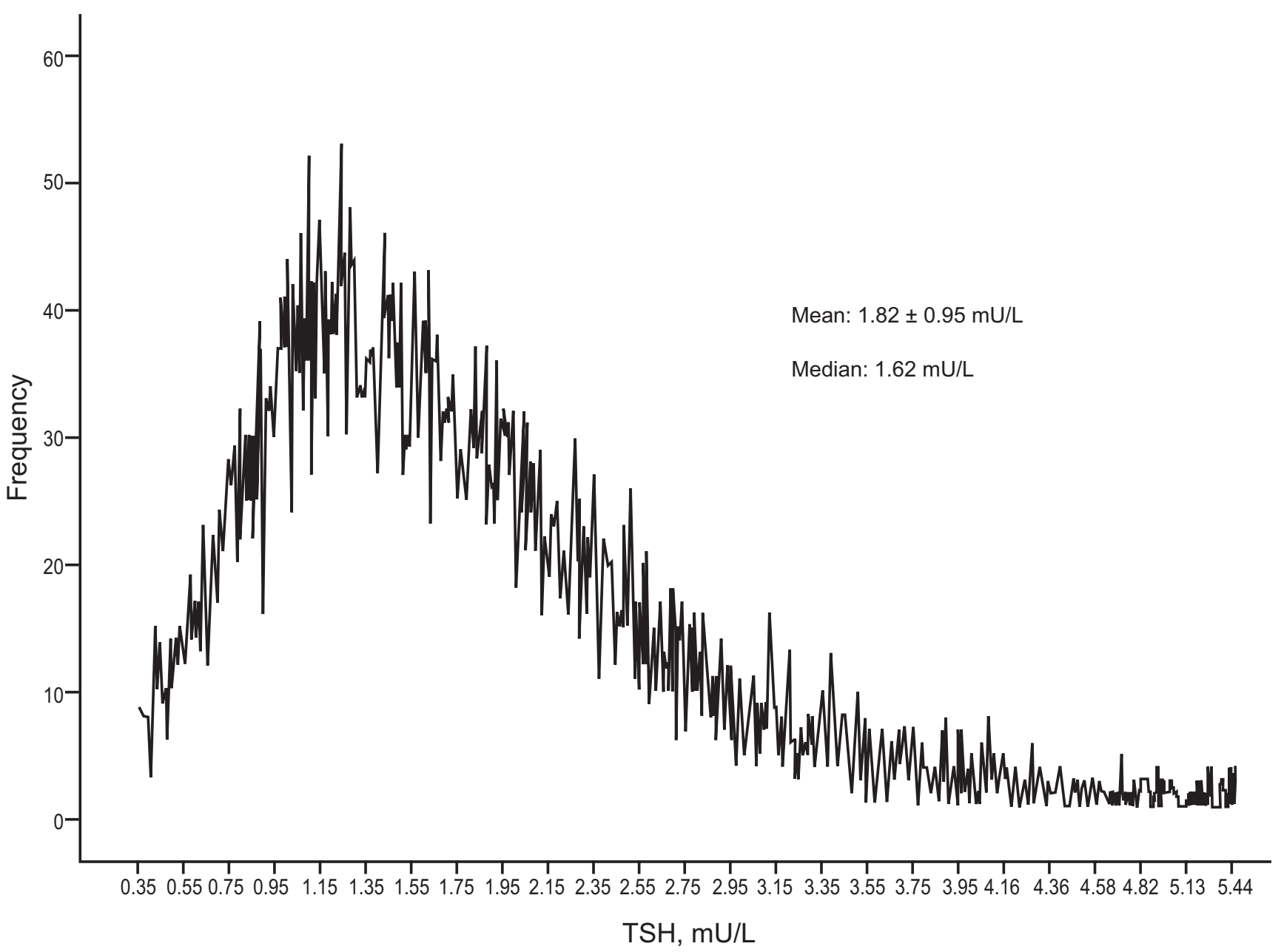

Figure 1. Distribution of thyroid stimulating hormone (TSH) concentrations in the study population.

\section{RESULTS}

\section{Population characteristics and TSH concentra- tions}

The characteristics of the 7,270 subjects are shown in Table 1. We studied 4,168 males and 3,102 females aged 20-89 years. Age distribution was similar in males and females. The mean TSH level of the study population was $1.82 \pm 0.95 \mathrm{mU} / \mathrm{L}$ (median, 1.62). The TSH concentration in males was significantly lower than that in females (1.67 \pm 0.87 vs. $2.02 \pm 1.01 \mathrm{mU} / \mathrm{L}$, respectively, $p<0.001)$. The TSH distribution was skewed toward the high end; the distribution pattern in males and females was similar (data not shown). When the 2.5 and 97.5 percentiles were calculated, 95\% TSH reference limits were 0.52-4.29 mU/L (Fig. 1).

\section{Factors associated with TSH concentration}

Table 2 shows the association of TSH concentration with multiple factors. Subjects were divided into five subgroups according to age. As expected, those over 60 years had higher TSH concentrations than other age groups ( $p$ $<$ o.01), although TSH concentration difference among each age group younger than 60 years old was not statistically significant. Also, TSH during winter was significantly higher than during other seasons (spring, $1.79 \pm 0.93 \mathrm{mU} / \mathrm{L}$; summer, $1.74 \pm 0.93 \mathrm{mU} / \mathrm{L}$; fall, $1.78 \pm 0.92 \mathrm{mU} / \mathrm{L}$; winter, $2.09 \pm 1.06 \mathrm{mU} / \mathrm{L} ; p<0.01)$. Obese males had a higher TSH concentration than did non-obese males $(2.00 \pm 1.00$ vs. $1.63 \pm 0.84 \mathrm{mU} / \mathrm{L} ; p<0.01)$. However, this was not observed in females, though there was a tendency toward a higher TSH in obese women $(2.09 \pm 1.05$ vs. $1.73 \pm 0.93$ $\mathrm{mU} / \mathrm{L}, p=0.064)$. Postmenopausal females showed a slightly higher TSH concentration than did premenopausal 
Table 2. TSH levels according to age, season, BMI, and menopause status

\begin{tabular}{|c|c|c|c|c|}
\hline \multicolumn{2}{|l|}{ Variables } & No. & $\mathrm{TSH}, \mathrm{mU} / \mathrm{L}$ & $p$ value \\
\hline \multicolumn{5}{|c|}{ Age group, yr } \\
\hline \multicolumn{2}{|l|}{$\leq 29$} & - & $1.87 \pm 1.00$ & \\
\hline \multicolumn{2}{|l|}{$30-39$} & - & $1.84 \pm 0.93$ & \\
\hline \multicolumn{2}{|l|}{$40-49$} & - & $1.77 \pm 0.93$ & \\
\hline \multicolumn{2}{|l|}{$50-59$} & - & $1.81 \pm 0.97$ & \\
\hline \multicolumn{2}{|l|}{$\geq 60$} & - & $1.93 \pm 1.02$ & $<0.01^{\mathrm{a}}$ \\
\hline \multicolumn{5}{|l|}{ Season } \\
\hline \multicolumn{2}{|c|}{ Spring (Mar-May) } & 1,927 & $1.79 \pm 0.93$ & \\
\hline \multicolumn{2}{|c|}{ Summer (Jun-Aug) } & 2,396 & $1.74 \pm 0.91$ & \\
\hline \multicolumn{2}{|c|}{ Fall (Sep-Nov) } & 1,820 & $1.78 \pm 0.92$ & \\
\hline \multicolumn{2}{|c|}{ Winter (Dec-Feb) } & 1,127 & $2.09 \pm 1.06$ & $<0.01^{b}$ \\
\hline \multicolumn{5}{|c|}{ Obesity (BMI $\geq 25 \mathrm{~kg} / \mathrm{m}^{2}$ ) } \\
\hline \multirow[t]{2}{*}{ Male } & Yes & 1,657 & $2.00 \pm 1.00$ & $<0.01$ \\
\hline & No & 2,511 & $1.63 \pm 0.84$ & \\
\hline \multirow[t]{2}{*}{ Female } & Yes & 517 & $2.09 \pm 1.05$ & 0.064 \\
\hline & No & 2,585 & $1.73 \pm 0.93$ & \\
\hline \multicolumn{5}{|c|}{ Menopause } \\
\hline \multicolumn{2}{|c|}{ Pre-menopause } & 2,610 & $2.00 \pm 0.99$ & \\
\hline \multicolumn{2}{|c|}{ Menopause } & 492 & $2.12 \pm 1.09$ & 0.01 \\
\hline
\end{tabular}

TSH, thyroid stimulating hormone; BMI, body mass index.

${ }^{a}$ Significant only between age group $\geq 60$ and other ages.

${ }^{\mathrm{b}}$ Significant only between winter and other seasons.

Table 3. Correlation coefficients between serum thyroid stimulating hormone and lipid levels

\begin{tabular}{|c|c|c|c|}
\hline & Serum lipid & $\beta$ & $p$ value \\
\hline \multirow[t]{4}{*}{ Model $1^{a}$} & Total cholesterol & 0.035 & 0.003 \\
\hline & Triglyceride & -0.005 & 0.367 \\
\hline & High-density lipoprotein cholesterol & 0.056 & 0.001 \\
\hline & Low-density lipoprotein cholesterol & 0.016 & 0.170 \\
\hline \multirow[t]{4}{*}{ Model $2^{b}$} & Total cholesterol & 0.048 & 0.001 \\
\hline & Triglyceride & 0.039 & 0.001 \\
\hline & High-density lipoprotein cholesterol & 0.003 & 0.780 \\
\hline & Low-density lipoprotein cholesterol & 0.035 & 0.003 \\
\hline
\end{tabular}

annadjusted data.

${ }^{\mathrm{b}}$ Adjusted for sex, age, season, menopause status, and obesity.

females ( $2.12 \pm 1.09$ vs. $2.00 \pm 0.99, p<0.01)$.

\section{Serum lipid profile}

Table 3 shows the association between serum TSH within the reference range and lipid concentration. There was a significant positive correlation between TSH and total cholesterol $(p=0.003)$. After adjustment for age, sex, season, menopause status, and obesity, we found clear positive correlations of TSH with total cholesterol ( $p=0.001)$, triglyceride ( $p=0.001)$, and LDL cholesterol $(p=0.003)$, but not HDL cholesterol $(p=0.780)$. 
Table 4. ORs for metabolic syndrome by TSH concentration

\begin{tabular}{lrccc}
\hline TSH, mU/L & No. & No. of metabolic syndrome & OR & $95 \% \mathrm{Cl}$ \\
\hline $0.35-1.38$ & 2,502 & 308 & 1.0 (Ref) & 1.112 \\
$1.39-2.41$ & 2,520 & 345 & 1.250 & $0.945-1.309$ \\
$2.42-3.44$ & 949 & 146 & 1.407 & $1.012-1.543$ \\
$3.45-4.47$ & 306 & 53 & 1.924 & $1.027-1.927$ \\
$4.48-5.5$ & 114 & 27 & $1.244-2.975$ \\
\hline
\end{tabular}

TSH, thyroid stimulating hormone; OR, odds ratio; $\mathrm{Cl}$, confidence interval; Ref, reference group.

\section{Metabolic syndrome}

The overall percentage of metabolic syndrome in euthyroid subjects according to the ATP III definition was 12.9 and $11.0 \%$ in males and females, respectively. Table 4 shows the prevalence of metabolic syndrome in five groups stratified by TSH concentration. The percentage of subjects with metabolic syndrome consistently and significantly increased with TSH concentration $(p<0.05)$.

\section{DISCUSSION}

The definition of the normal range of serum TSH remains controversial. This issue is important because the normal range provides a framework to categorize patients as normal or as having subclinical or overt thyroid disease.

We report the findings of our population-based study on the reference range of TSH concentration and the association of TSH with lipid concentration and metabolic syndrome. TSH was negatively correlated with lipid concentration after adjustment for factors that can affect its concentration. Furthermore, we found that participants with high-normal TSH levels had an almost two-fold higher risk of metabolic syndrome compared to those within reference group. These findings are consistent with the well-established relationship between overt hypothyroidism and lipid concentration [15]. Several epidemiologic studies have shown that increased lipid concentration is associated with (subclinical) hypothyroidism; this explains the increased prevalence of cardiovascular disease in patients with (subclinical) hypothyroidism [7,9,16,17]. These phenomena are obvious in hypothyroidism but remain controversial in subclinical hypothyroidism. This argument raises the question of the normal range of TSH concentration $[5,6,18]$.

The lower limit of TSH is less debated; most discussions are of how to define the upper limit of TSH, suggesting that the upper normal limit should be decreased to $2.5 \mathrm{mU} / \mathrm{L}$ [19]. A growing body of literature describes the adverse effects of subclinical thyroid disease and the benefits of $\mathrm{T}_{4}$ treatment [20-23]. Moreover, new National Academy of Clinical Biochemistry (NACB) guidelines state that more than 95\% of healthy, euthyroid subjects had a serum TSH concentration of 0.4-2.5 mU/L [19]. The mean TSH concentration in our study was $1.81 \pm 0.95 \mathrm{mU} / \mathrm{L}$; this is lower than the median value, and the distribution curve was skewed to the right. Total cholesterol, triglyceride, and LDL cholesterol levels increased with TSH level within the reference range, as did the prevalence of metabolic syndrome. It is noteworthy that the positive association between serum lipid levels and TSH concentration was still significant after adjustment for several confounding variables such as age, sex, and obesity. Our study emphasized that people who are categorized as being euthyroid are susceptible to metabolic syndrome, itself a cluster of cardiovascular risk factors. Increased TSH concentration, even within the currently accepted reference range, may have long-term detrimental effects on cardiovascular health. Therefore, subjects with high normal TSH should be carefully assessed for early thyroid dysfunction, which is a risk factor for atherosclerosis.

TSH can be influenced by several factors. TSH shows diurnal variation, being high at night and low in the morning [24]. Fasting status [25] and estrogen [26] also affect TSH levels. However, conflicting factors such as fasting status or diurnal change were excluded in our study because all blood samples were taken at 8-10 AM, after fasting. Thyroid dysfunction in the elderly is more prevalent than in the young [27]. Moreover, the prevalence of thyroglobulin 
antibodies and thyroid peroxidase antibodies increases with age, according to the NHANES III report [27]. Therefore, our report of increased TSH concentration in subjects above 60 years is consistent with these data.

Data in the United States National Health and Nutrition Examination Survey (NHANES) suggested that TSH levels differ between Blacks and Whites in the US [28]. Several epidemiologic studies have reported the normal range of TSH concentration in the Korean population [2932]. These studies show a slightly different TSH reference range from that in American or European populations. Lee et al. [29] reported 0.39-3.68 mIU/L in 317 patients, Jung et al. [30] 0.34-3.28 mIU/L, and Jang et al. [31] 0.47$8.76 \mathrm{mIU} / \mathrm{L}$ as a TSH normal reference range. Our study included a relatively large population and different age groups. However, further studies are required to document the normal reference range in the Korean population, and the relationship with clinical presentation should be considered.

The limitation of our study is that it was a cross-sectional, so a cause and effect relationship cannot be discerned. However, this study included a rather large number of subjects who visited our clinics for a routine health check-up and are considered to be healthy members of the general population. Also, we could not obtain data regarding thyroid autoimmunity, which represents unreported underlying thyroid disease and may influence TSH concentration. Subjects with thyroid auto-antibody positivity tend to have higher TSH concentrations regardless of ethnicity [27]. If we exclude participants who may have been antibodypositive, the TSH reference range would be narrower than that found in this study. Finally, we checked TSH only once, even though whether a single TSH measurement reflects the individual's average TSH measurement over time remains unknown.

In summary, we report a population-based TSH reference range of 0.52-4.29 mU/L in a general Korean population sample. TSH concentration was influenced by age, sex, season, menopausal status and obesity (in males only). Further, TSH concentration within the normal range was negatively correlated with serum lipid level, and highnormal TSH levels were significantly associated with an increased prevalence of metabolic syndrome. An additional study is needed to define TSH concentration and should include measurement of thyroid auto-antibody. This will provide evidence of the optimal method of treating early- stage mild thyroid dysfunction. The clinical significance of high-normal TSH levels with regard to cardiovascular prognosis should be determined in prospective studies.

\section{Conflict of interest}

No potential conflict of interest relevant to this article was reported.

\section{REFERENCES}

1. Kronenberg HM, Williams RH. Thyroid physiology and diagnostic evaluation of patients with thyroid. In: Kronenberg HM, Melmed S, Polonsky KS, Larsen PR, eds. Williams Textbook of Endocrinology. 11th ed. Philadelphia: Saunders, 2008:312-313.

2. Klee GG, Hay ID. Biochemical testing of thyroid function. Endocrinol Metab Clin North Am 1997;26:763-775.

3. Fatourechi V. Adverse effects of subclinical hyperthyroidism. Lancet 2001;358:856-857.

4. Cooper DS. Subclinical thyroid disease: consensus or conundrum? Clin Endocrinol (Oxf) 2004;60:410-412.

5. Surks MI, Goswami G, Daniels GH. The thyrotropin reference range should remain unchanged. J Clin Endocrinol Metab 2005;90:5489-5496.

6. Wartofsky L, Dickey RA. The evidence for a narrower thyrotropin reference range is compelling. J Clin Endocrinol Metab 2005;90:5483-5488.

7. Cappola AR, Ladenson PW. Hypothyroidism and atherosclerosis. J Clin Endocrinol Metab 2003;88:2438-2444.

8. Klein I, Ojamaa K. Thyroid hormone and the cardiovascular system. N Engl J Med 2001;344:501-509.

9. Canaris GJ, Manowitz NR, Mayor G, Ridgway EC. The Colorado thyroid disease prevalence study. Arch Intern Med 2000;160:526-534.

10. Caraccio N, Ferrannini E, Monzani F. Lipoprotein profile in subclinical hypothyroidism: response to levothyroxine replacement, a randomized placebo-controlled study. J Clin Endocrinol Metab 2002;87:1533-1538.

11. Iqbal A, Jorde R, Figenschau Y. Serum lipid levels in relation to serum thyroid-stimulating hormone and the effect of thyroxine treatment on serum lipid levels in subjects with subclinical hypothyroidism: the Tromso Study. J Intern Med 2006;260:5361.

12. Michalopoulou G, Alevizaki M, Piperingos G, et al. High serum cholesterol levels in persons with 'high-normal' TSH levels: should one extend the definition of subclinical hypothyroidism? Eur J Endocrinol 1998;138:141-145.

13. Inoue S, Zimmet $P$, Caterson I, Chunming C, Ikeda $Y$, Khalid A. The Asia-Pacific Perspective: Redefining Obesity and Its Treat- 
ment. Sydney: Health Communications Australia Pty, 2000.

14. Alberti KG, Zimmet P, Shaw J. Metabolic syndrome-a new world-wide definition: a Consensus Statement from the International Diabetes Federation. Diabet Med 2006;23:469-480.

15. Duntas LH. Thyroid disease and lipids. Thyroid 2002;12:287293.

16. Surks MI, Ortiz E, Daniels GH, et al. Subclinical thyroid disease: scientific review and guidelines for diagnosis and management. JAMA 2004;291:228-238.

17. Walsh JP, Bremner AP, Bulsara MK, et al. Subclinical thyroid dysfunction as a risk factor for cardiovascular disease. Arch Intern Med 2005;165:2467-2472.

18. Dickey RA, Wartofsky L, Feld S. Optimal thyrotropin level: normal ranges and reference intervals are not equivalent. Thyroid 2005;15:1035-1039.

19. Baloch Z, Carayon P, Conte-Devolx B, et al. Laboratory medicine practice guidelines: laboratory support for the diagnosis and monitoring of thyroid disease. Thyroid 2003;13:3-126.

20. Jorde R, Waterloo K, Storhaug H, Nyrnes A, Sundsfjord J, Jenssen TG. Neuropsychological function and symptoms in subjects with subclinical hypothyroidism and the effect of thyroxine treatment. J Clin Endocrinol Metab 2006;91:145-153.

21. McDermott MT, Ridgway EC. Subclinical hypothyroidism is mild thyroid failure and should be treated. J Clin Endocrinol Metab 2001;86:4585-4590.

22. Ineck BA, Ng TM. Effects of subclinical hypothyroidism and its treatment on serum lipids. Ann Pharmacother 2003;37:725730.

23. Kim SK, Kim SH, Park KS, Park SW, Cho YW. Regression of the increased common carotid artery-intima media thickness in subclinical hypothyroidism after thyroid hormone replacement. Endocr J 2009;56:753-758.

24. Persani L, Terzolo M, Asteria C, Orlandi F, Angeli A, Beck-
Peccoz P. Circadian variations of thyrotropin bioactivity in normal subjects and patients with primary hypothyroidism. J Clin Endocrinol Metab 1995;80:2722-2728.

25. Scobbo RR, VonDohlen TW, Hassan M, Islam S. Serum TSH variability in normal individuals: the influence of time of sample collection. W V Med J 2004;100:138-142.

26. Schindler AE. Thyroid function and postmenopause. Gynecol Endocrinol 2003;17:79-85.

27. Spencer CA, Hollowell JG, Kazarosyan M, Braverman LE. National Health and Nutrition Examination Survey III thyroidstimulating hormone (TSH)-thyroperoxidase antibody relationships demonstrate that TSH upper reference limits may be skewed by occult thyroid dysfunction. J Clin Endocrinol Metab 2007;92:4236-4240.

28. Hollowell JG, Staehling NW, Flanders WD, et al. Serum TSH, $\mathrm{T}(4)$, and thyroid antibodies in the United States population (1988 to 1994): National Health and Nutrition Examination Survey (NHANES III). J Clin Endocrinol Metab 2002;87:489499.

29. Lee DC, Shim JY, Lee HR. The usefulness of serum thyrotropin (TSH) as a screening test for thyroid disease. J Korean Acad Fam Med 1995;16:443-453.

30. Jung SW, Chang SY, CHO JJ. Prevalence of abnormal thyroid function test and significance of TSH in health examination. $\mathrm{J}$ Korean Acad Fam Med 1993;14:752-759.

31. Jang HW, Lee JI, Shin HW, et al. Reference range of serum TSH with aging and prevalence of subclinical hypothyroidism in patients without history of thyroid disease for the general medical examination. J Korean Thyroid Assoc 2009;2:28-32.

32. Jang YY, Kim CY, Hwang TY, Kim KD, Lee CH. Reference interval of serum thyroid hormones in healthy Korean adults. J Prev Med Public Health 2008;41:128-134. 